\title{
Erratum to: Continuous Positive Airway Pressure for Spontaneously Breathing Premature Infants with Respiratory Distress Syndrome
}

\author{
Ashok Saxena • R. K. Thapar • Vishal Sondhi • \\ Parijat Chandra
}

Published online: 8 June 2012

(C) Dr. K C Chaudhuri Foundation 2012

\section{Erratum to: Indian J Pediatr}

\section{DOI 10.1007/s12098-012-0722-z}

The original version of this article unfortunately contained mistakes.

Legend of table 3 should be corrected and read as 'Time to reach full feeds and time to regain birth weight for neonates $\leq 30$ wk'.

In addition, the correct affiliation of Ashok Saxena, corresponding author, is 155 Base Hospital, c/o 99 APO.

The online version of the original article can be found at http://dx.doi.org/ 10.1007/s12098-012-0722-z.

\footnotetext{
A. Saxena $(\bowtie)$

Department of Pediatrics and Neonatology,

155 Base Hospital, c/o 99 APO

e-mail: ashok_neosaxena@yahoo.co.in

R. K. Thapar

Neonatal Division, Department of Pediatrics, Command Hospital,

Kolkatta, India

V. Sondhi

Department of Pediatrics, Military Hospital,

Ambala, India

P. Chandra

Vitreoretina and ROP Services, Dr. Rajendra Prasad Centre

for Ophthalmic Sciences, All India Institute of Medical Sciences,

New Delhi, India
} 